\title{
The Swiss National Cohort: a unique database for national and international researchers
}

\author{
Adrian Spoerri • Marcel Zwahlen • Matthias Egger • \\ Matthias Bopp
}

Published online: 17 June 2010

(C) Swiss School of Public Health 2010

\section{Introduction}

Longitudinal studies, also known as cohort studies, collect data on a large number of individuals at different points in time. These studies allow tracking changes of health status, presence of diseases and risk factors in human populations. Many longitudinal studies of large parts or the whole resident population have been established in the United Kingdom and in Nordic countries where population registries and unique person identifiers facilitate the linkage of existing databases. In contrast, information on the health of the Swiss population is limited. The Swiss Health Surveys are cross-sectional and the few existing prospective studies are not representative for the population at large. Death certificate data have been used to describe differentials in mortality by occupation (Minder et al. 1986) but analyses used proportionate mortality and excluded older men and many women. The Swiss National Cohort (SNC) was set up to improve this situation by providing a national data platform and developing a multi-faceted research programme. Following several pilot projects, the SNC has been funded by the Swiss National Science Foundation since 2006.

Adrian Spoerri, Marcel Zwahlen, Matthias Egger, Matthias Bopp: for the Swiss National Cohort Study.

\footnotetext{
A. Spoerri $(\bowtie) \cdot M$. Zwahlen · M. Egger

Finkenhubelweg 11, 3012 Bern, Switzerland

e-mail: spoerri@ispm.unibe.ch

\section{Bopp}

Institute of Social and Preventive Medicine,

University of Zürich, Hirschengraben 84,

8001 Zürich, Switzerland
}

Institute of Social and Preventive Medicine, University of Bern,

\section{Anatomy of the SNC}

Described in detail elsewhere (Bopp et al. 2009), the SNC is a longitudinal study of the entire resident population of Switzerland, based on the national censuses. The 1990 census records were linked to either a 2000 census, a death or an emigration record. In the absence of names or a unique personal identifier, linkage used a combination of deterministic and probabilistic methods, based on sex, date of birth, marital status, nationality, religion, place of residence and other variables. The Generalized Record Linkage System package developed by Statistics Canada (Fair 2004) was used. At present, the cohort is based on the 1990 census, with mortality follow-up to the year 2008 and 108.3 Mio years of follow-up (Fig. 1).

\section{Questionnaires and outcomes}

All variables from the 1990 census are available in the SNC, and additional questions were introduced in 2000 . The census consists of three questionnaires: one for each person (102 variables in 1990, 172 in 2000), a household questionnaire (161 variables in 1990, 204 in 2000) and a questionnaire on the building (66 variables 1990, 48 in 2000). All questionnaires are available at http://www.swiss nationalcohort.ch. All-cause and cause-specific mortality are the main outcomes, with cause of death coded according to the International Classification of Diseases, Injuries and Causes of Death (version 8 until 1994 and version 10 since 1995).

\section{Limitations}

Not all mortality records could successfully be linked to individuals included in the cohort. Of the 1,122,376 deaths 


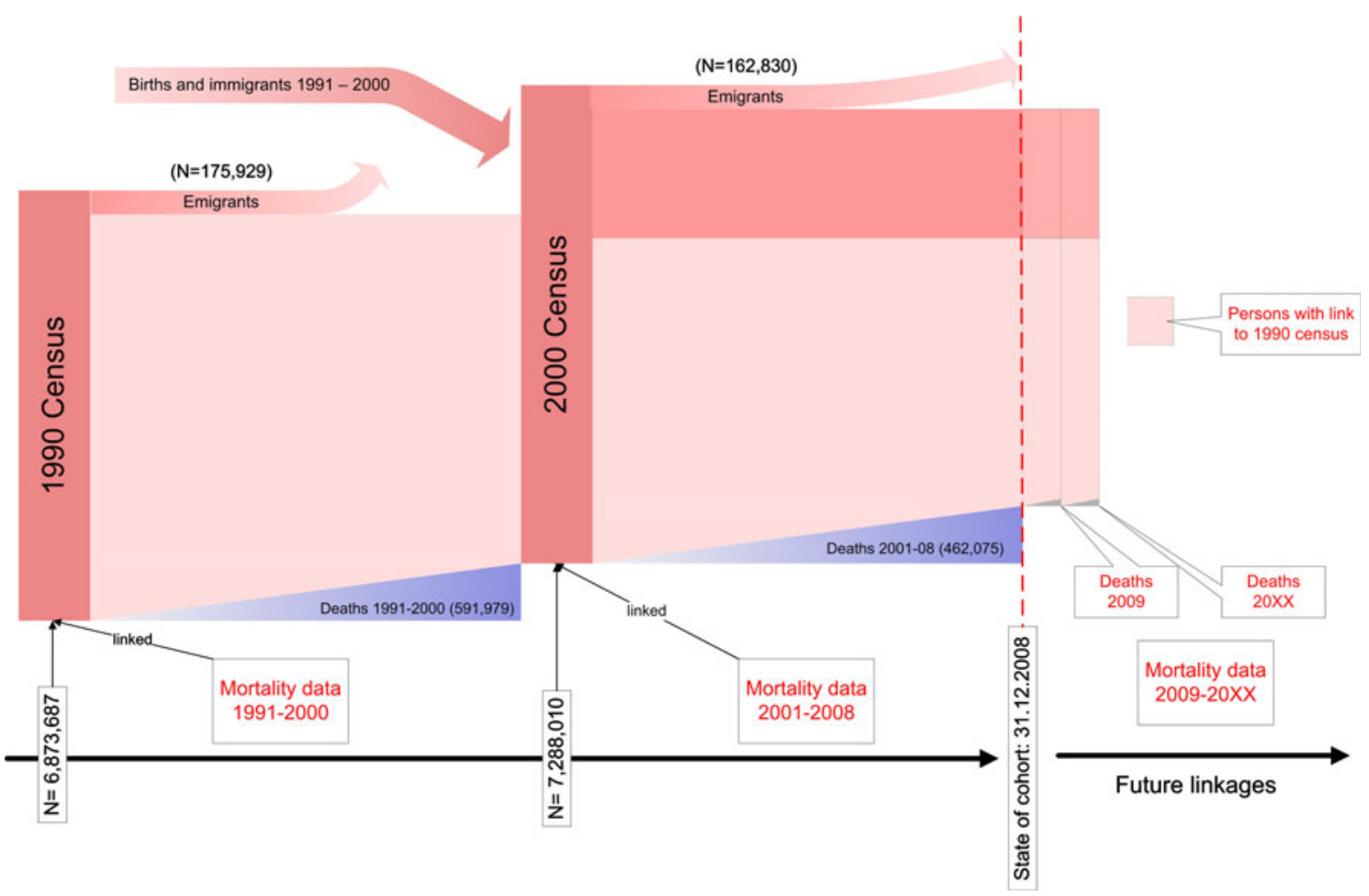

Fig. 1 Structure of the Swiss National Cohort

recorded from 5 December 1990 (the day after the census) to the end of 2008, 1,052,527 (93.8\%) deaths could be linked to a 1990 or 2000 census record. Unlinked deaths were younger at death, less likely to be Swiss nationals and more likely to be women and single. Also, for 476,814 (6.9\%) individuals registered in the 1990 census no satisfactory link to a mortality record, emigration record or year 2000 census record could be found. The majority of unlinked records relate to individuals aged 10-29 years. The lower linkage rates among young adults are probably due to their high mobility and residence in larger cities, which makes linkage more difficult. The accuracy of death certificates is also of concern. As for other studies relying on official mortality records, the quality of the data is probably satisfactory for malignant neoplasms, cerebrovascular disease, ischaemic heart disease and accidents, but less reliable for diseases of the nervous system, chronic respiratory conditions and other types of heart disease. Finally, the information on socio-economic status is limited by the fact that the census did not collect information on income, capital or other assets.

\section{Analyses}

In recent years projects examining socio-economic and environmental factors have been completed and reported in the literature. Analyses of the SNC showed pronounced social gradients in life expectancy by education. Men aged 30 with university degrees can expect to live 7.1 years longer than men with compulsory schooling only (Spoerri et al. 2006). Another study found an increased risk of Alzheimer disease in people who had lived within $50 \mathrm{~m}$ of a $220-380 \mathrm{kV}$ power line for at least 15 years (Huss et al. 2009). Mortality from coronary heart disease was found to decline by $22 \%$ for each $1,000 \mathrm{~m}$ increase in the altitude of the place of residence (Faeh et al. 2009). The SNC also contributed to a better understanding of the risk of suicide in HIV-infected patients before and after the introduction of potent antiretroviral therapies (Keiser et al. 2010). The study also participated in several European collaborative analyses (Borrell et al. 2005; Huisman et al. 2004, 2005; Menvielle et al. 2008; Strand et al. 2007). Other projects are awaiting publication, including studies of the role of religion in suicide, studies on risk factors for fatal road traffic accidents, aircraft noise and fatal myocardial infarction and the association between socio-economic position and the risk of childhood cancer. Appendix gives a list of publications and ongoing and planned projects.

\section{Discussion and outlook}

The SNC is unique in several ways. It is one of the largest population-based cohorts worldwide, covering several distinct cultural, linguistic and geographical regions within 
the same health care system. A wealth of baseline information is available from the census, including detailed questionnaires at the level of the person, household and dwelling, with information that is not generally available in longitudinal studies. Because each building is geo-referenced, geographically determined exposures can be studied. Planned work include the development of an areabased indicator of socio-economic status for use in health research in Switzerland; examining the socio-economic determinants of mortality in the old and very old; and the epidemiology of specific causes of death (such as perinatal deaths and cancer-related deaths). Projects that will link the SNC with other data to address specific questions (for example the association of birth weight with childhood mortality or the epidemiology of multiple person killings) are in preparation. Evidently, all studies obtain ethical approval and follow rules for data protection.

The SNC is a resource that is available to any interested national or international researchers (see http://www.swiss nationalcohort.ch). Access to raw and tabulated data has to be approved by the Federal Office of Statistics, who owns the data. We invite interested parties to contact the study team (snc_info@ispm.unibe.ch) to discuss their project ideas.

\section{Appendix: Swiss National Cohort: completed, ongoing and planned projects}

Completed projects

1. Spoerri A, Zwahlen M, Egger M, Gutzwiller F, Minder C, Bopp M (2006) Educational inequalities in life expectancy in German speaking part of Switzerland 1990-1997: Swiss National Cohort. Swiss Med Wkly 136:145-148.

2. Huss A, Spoerri A, Egger M, Roosli M (2009) Residence near power lines and mortality from neurodegenerative diseases: longitudinal study of the Swiss population. Am J Epidemiol 169:167-175.

3. Faeh D, Minder C, Gutzwiller F, Bopp M (2009) Culture, risk factors and mortality: can Switzerland add missing pieces to the European puzzle? JECH 2009. J Epidemiol Community Health 63:639-645

4. Faeh D, Gutzwiller F, Bopp M (2009) Lower mortality from coronary heart disease and stroke at higher altitudes in Switzerland. Circulation 120:495-501.

5. Keiser O, Spoerri A, Brinkhof MW et al (2010) Suicide in HIV-infected individuals and the general population in Switzerland, 1988-2008. Am J Psychiatry $167: 143-150$.

6. Huss A, Spoerri A, Egger M, Roeoesli M (2010) Aircraft noise, air pollution and mortality from myocardial infarction in Switzerland: national cohort study. Epidemiology (in press).

7. Spoerri A, Zwahlen M, Bopp M, Gutzwiller F, Egger M (2010) Religion and assisted and non-assisted suicide: a national cohort. Int J Epidemiol (in press).

8. Spoerri A, Egger M, Von Elm E (2010) Mortality from road traffic accidents in Switzerland: longitudinal and spatial analyses. Accid Anal Prev (in press).

9. Adam M, Spoerri A, Schmidlin K, Gumy-Pause F, Brazzola P, Kuehni C et al (2009) What is the evidence on socio-economic status and the risk of childhood leukemia in Switzerland? (submitted).

Ongoing projects

- Marital status and mortality: is the association modified by gender?

- Development of an area-based socio-economic index

- Childhood cancer and nuclear power plants in Switzerland

- Cancer epidemiology in older adults: population-based research of trends and factors associated with cancer mortality in Switzerland, 1990-2007

- Socio-economic position and treatment response and outcomes of HAART

- Municipality tax rate, individual socio-economic status and health disparities: where (not) to live in Switzerland

- Spatial distribution of lung cancer mortality in Switzerland

- Swiss health atlas: spatial patterns of mortality

- Language, regional diversity and alcohol related mortality

- Family drama: multi person killings in Switzerland

- Educational inequality in mortality in Europe (Eurothine).

Planned projects

- Linkage with Swiss Health Surveys

- Linkage of live births: socio-economic determinants of birth and childhood mortality

- Linkage with cancer registries: socio-economic and spatial epidemiology of cancer.

\section{References}

Bopp M, Spoerri A, Zwahlen M et al (2009) Cohort profile: the Swiss National Cohort-a longitudinal study of 6.8 million people. Int J Epidemiol 38:379-384 
Borrell C, Plasencia A, Huisman M et al (2005) Education level inequalities and transportation injury mortality in the middle aged and elderly in European settings. Inj Prev 11:138-142

Faeh D, Gutzwiller F, Bopp M (2009) Lower mortality from coronary heart disease and stroke at higher altitudes in Switzerland. Circulation 120:495-501

Fair M (2004) Generalized record linkage system-Statistics Canada's record linkage software. Austrian J Stat 33:37-53

Huisman M, Kunst AE, Andersen O et al (2004) Socioeconomic inequalities in mortality among elderly people in 11 European populations. J Epidemiol Community Health 58:468-475

Huisman M, Kunst AE, Bopp M et al (2005) Educational inequalities in cause-specific mortality in middle-aged and older men and women in eight western European populations. Lancet 365:493500

Huss A, Spoerri A, Egger M et al (2009) Residence near power lines and mortality from neurodegenerative diseases: longitudinal study of the Swiss population. Am J Epidemiol 169:167-175
Keiser O, Spoerri A, Brinkhof MW et al (2010) Suicide in HIVinfected individuals and the general population in Switzerland, 1988-2008. Am J Psychiatry 167:143-150

Menvielle G, Kunst AE, Stirbu I et al (2008) Educational differences in cancer mortality among women and men: a gender pattern that differs across Europe. Br J Cancer 98:1012-1019

Minder CE, Beer V, Rehmann R (1986) Sterblichkeitsunterschiede nach sozio-ökonomischen Gruppen in der Schweiz 1980:15 bis 74jährige Männer. Soz Praventivmed 31:216-219

Spoerri A, Zwahlen M, Egger M et al (2006) Educational inequalities in life expectancy in German speaking part of Switzerland 1990 1997: Swiss National Cohort. Swiss Med Wkly 136:145-148

Strand BH, Kunst A, Huisman M et al (2007) The reversed social gradient: higher breast cancer mortality in the higher educated compared to lower educated. A comparison of 11 European populations during the 1990s. Eur J Cancer 43:1200-1207 